\title{
Antropología y educación Nota sobre una difícil relación conceptual
}

\author{
ANTONI J. Colom CAÑEllas \\ Universidad de las Islas Baleares \\ JOAN-CARLES MÈLICH SANGRÀ \\ Universidad Autónoma de Barcelona
}

\begin{abstract}
SUMMARY.-The aim of this article is to show the relationship between anthropology and education. Question about education and man does not constitute two different questions but just only one. In that way Anthropology of Education is not a marginal discipline within educational sciences but just the opposite.
\end{abstract}

«El hombre es algo que debe ser superado. ¿Qué habéis hecho para superarlo?

Todos los seres han creado hasta ahora algo por encima de ellos mismos: ¿y queréis ser vosotros el reflujo de esta gran marea y retroceder al animal más bien que superar al hombre?

(F. Nietzsche, Así habló Zaratustra)

La relación entre las ciencias humanas en general y la antropología en particular parece estar establecida cuanto menos desde la filosofía kantiana, al afirmar éste que todas las preguntas filosóficas podían resumirse en una sola: ¿qué es el hombre?

De ser esto cierto, se podría sostenerse algo parecido respecto a las ciencias de la educación o incluso más aún de la pedagogía. Si el objeto de ésta es la descripción, comprensión y normatividad del fenómeno educativo entonces resulta que la pregunta por la educación y por el hombre no son dos cuestiones distintas sino una sola. Abordar los problemas pedagógicos significa habérselas necesariamente con la realidad humana, y viceversa. Incluso en el caso de una teoría o filosofía de la educación de las llamadas «antihumanistas» (Foucault o Luhmann, por poner un ejemplo), debe quedar clara la relación que se establece entre la «estructura» o el «sistema social» y la realidad humana. Al considerarse esta cuestión se construye de nuevo el puente entre la teoría/filosofía de la educación y la antropología. Convertir al hombre en un «entorno» de los sistemas sociales, como lo hace Luhmann, por poner un ejemplo, es ya tomar una determinada «posición» antropológica. En definitiva, la primera idea que queremos establecer no es otra que la siguiente: la antropología de la educación no es una disciplina marginal dentro de las llamadas ciencias de la educación, sino todo lo contrario. Una segunda perspectiva se centraría en reconocer calidad de enfoque a la Antropología de la Educación, en el sentido que muy fácilmente puede superar los planteamientos de una disciplina para convertirse en una forma o manera de abordar el estudio pedagógico. 


\section{LA ACCIÓN EDUCATIVA COMO ACCIÓN SOCIAL}

El pensamiento contemporáneo ha desarrollado una tesis, a nuestro juicio de vital importancia, que vincula esencialmente el ser humano al fenómeno educativo: nos referimos a la categoría de «inacabamiento», o si se quiere de «apertura». Al respecto es conocida la afirmación de Karl Jaspers: «Ser hombre es llegar a ser hombre» (Menschsein ist Menschwerden) (Jaspers, 1983, p. 57). Mientras que «el mundo animal» aparece «cerrado», el mundo humano» está abierto, indefinido ${ }^{1}$. El anthropos es un no ser todavía, un proyecto, una posibilidad. Heidegger, en Ser y Tiempo insiste en esta dimensión antropológica, hasta el punto de construir toda su «trama categorial» alrededor del «existenciario» de la «cura», «cuidado» o «preocupación», (Sorge, en alemán) ${ }^{2}$.

La «precariedad ontológica» del ser humano se manifiesta en su estructura biológi$\mathrm{ca}^{3}$. No hay un «mundo del hombre», es decir, un entorno «sólidamente estructurado por la organización de sus propios instintos» ${ }^{4}$. Como advierten Peter Berger y Thomas Luckmann, el mundo del hombre es «abierto», a diferencia de todos los otros animales que viven en universos «cerrados», cuyas estructuras están predeterminadas por su equipaje biológico.

La apertura del mundo antropológico se traduce también en una «carencia», en una «falta de...». Esta carencia queda compensada por la sociedad, por la cultura, por la civilización. «Cultura» puede entenderse aquí como «concepción del mundo» o «cosmovisión» (Weltanschauung).

Resulta epistemológicamente útil la distinción entre «cultura» y «civilización». La primera es un elemento de la segunda. En otras palabras, la civilización engloba la cultura, la concepción del mundo, aunque no se reduce a ella. Contamos además con todo el ámbito del «saber hacer», de lo tecnológico, así como de lo institucional, de la organización del mundo (Véase la figura 1).

\section{CULTURA \\ TÉCNICAS \\ INSTITUCIONES}

\section{CONCEPCIÓN DEL MUNDO TRANSFORMACIÓN DEL MUNDO ORGANIZACIÓN DEL MUNDO}

(Los elementos de la «civilización).

Dentro del apartado cultural no debe olvidarse lo que se conviene habitualmente en denominar «imaginario simbólico» ${ }^{5}$. La concepción del mundo antropológica es simbó-

1. Arnold Gehlen escribe al respecto: «A diferencia del animal, el hombre está entregado a un mundo indefinido, infinitamente abierto, con una multitud de posibilidades imprevistas (...). El hombre ha sido arrojado inerme, sin interés ni especialización, es decir, inadaptado, a un mundo que es de contenido tan inmensamente rico justamente porque agobia e inunda de impresiones a un ser carente de esa limitación orgánica protectora que posee el animal, el cual puede vivir en su cuerpo gracias a que armoniza con el medio» (Gehlen, 1993, p. 48).

2. Cfr. Heidegger (1979), Sein und Zeit, concretamente el capítulo titulado: «Die Sorge als Sein des Daseins».

3. Véase Plessner (1975), Die Stufen des Organischen und der Mensch, pp. 288 y ss.

4. Berger y Luckmann sostienen al respecto: «Unlike the other higher mammals, he has no species-specific environment, no environment firmly structured by his own instinctual organization. There is no man-world in the sense that one may speak of a dog-world or a horse-world» (1991, p. 65).

5. Recurrimos a un fragmento Clifford Geertz para ilustrarlo: «El hombre, ese animal que fabrica herramientas, que ríe o que miente, es también un animal incompleto, o más exactamente, un 
lica, y la educación, en la medida en que es una acción social puede definirse también como «acción simbólica».

El ser humano es un ser social. Ante todo y sobre todo se construye a sí mismo en un entorno socio-cultural. Sin embargo, esa «construcción» es el resultado siempre inacabado de la interacción con los otros. Desde este punto de vista, la educación es un proceso, pero un proceso interactivo, es decir, una acción social.

Todavía hoy debemos recurrir a Max Weber para clarificar el significado de «acción social». En su obra Economía y sociedad, Weber comienza dándonos esta definición:

Por «acción» debe entenderse una conducta humana (bien consista en una hacer externo o interno, ya en un omitir o permitir) siempre que el sujeto o los sujetos de la acción enlacen a ella un sentido subjetivo. La «acción social», por tanto, es una acción en donde el sentido mentado por su sujeto o sujetos está referido a la conducto de otros, orientándose por ésta en su desarrollo» (Weber, 1987, p. 5).

La educación es una acción social, y, por lo tanto, una acción antropológica. No debe entenderse aquí, empero, la educación como una mera acción socializadora pasiva, o como un proceso de enculturación, al modo de Durkeim. Aunque, en efecto, la educación también es enculturación, creemos que el fenómeno es más complejo. En la acción educativa lo que se forma es el «yo» del individuo, el «sí-mismo», el self . La construcción del «yo» es educativa; esto es: interactiva. El «otro» es la condición de posibilidad de la edificación del «yo». Es importante comprobar cómo la filosofía de Hegel, concretamente en su Fenomenología del Espíritu, ya anticipó mucho de lo que aquí se ha desarrollado $^{7}$. Incluso en Sartre ${ }^{8}$, el otro también me afecta aunque sea negativamente -en el plano de la educación hablaríamos junto con Fullat de violencia (con la consiguiente «agonía»)- degradando mi mismisidad -deconstrucción- por vía ontológica (conociendo al otro me doy cuenta de mi no ser). No hay duda, que como afirma G. Steiner (1991, 127) la Antropología tiene bastante de arqueología de la conciencia.

En su relación de alteridad el ser humano construye también modos de contemplación del mundo. Es la «construcción social de la realidad» que la «sociología del conocimiento» desarrolló con éxito. Pero el entorno humano, su Umwelt, no es solamente social, sino también físico. El orden físico le viene dado al sujeto. No obstante, el hombre no se limita a adaptarse al medio, sino que lo transforma, y lo transforma culturalmente, en función de esas pautas de conocimiento que posee. La biología humana no resistiría una mera adaptación. Gehlen lo vio así en el fragmento siguiente:

animal que se completa a sí mismo. Siendo agente de su propia realización, el hombre crea, valiéndose de su capacidad general para construir modelos simbólicos, las aptitudes específicas que lo definen. $\mathrm{O}$-para volver por fin a nuestro tema-el hombre se hace, para bien o para mal, un animal político por obra de la construcción de ideologías, de imágenes esquemáticas de orden social» (Geertz, 1991, p. 190).

6. La Escuela de Chicago y, en particular, George Herbet Mead, en su libro Espíritu, persona y sociedad (1982), lo estudió en detale.

7. Véase Hegel, Fenomenología del espíritu, Cap. IV: «Autoconciencia».

8. Sartre, J. P., en la tercera parte de El ser y la nada, es donde desarrolla más sistemáticamente su teoría negativista del otro. Hemos consultado la edición publicada en Buenos Aires, 1961, por edit. Ibero-americana ( $3 \mathrm{tms})$. 


\begin{abstract}
«En todo caso, se puede decir que el hombre, expuesto como el animal a la naturaleza agreste, con su físico y su deficiencia instintiva congénitos, sería en todas las circunstancias inapto para la vida. Pero esas deficiencias están compensadas por su capacidad de transformar la naturaleza inculta y cualquier ambiente natural, como quiera que esté constituido, de manera que se torne útil para su vida» (Gehlen, 1993, 33).
\end{abstract}

La antropología de la educación, entonces, deberá descubrir las «acciones pedagógicas» no solamente como procesos de enculturación pasiva, al modo clásico, sino como una actividad del sujeto. El hombre educando es el objeto de la acción educativa, pero no es un simple objeto. En su relación con las otras subjetividades las construye, las educa, y reconstruye a su vez su entorno. La antropología en este sentido incidiría sobre el hombre en su devenir. Es, de todas formas, una constante que se evidencia desde los pre-socráticos hasta nuestros días; los presocráticos se afiliaban a concepciones cosmológicas -el hombre en función del universo- o sea, tomaba conciencia de sí en cuanto él pero no como yo; en cambio, la concepción antropológica supone el universo en función del hombre, ya que es el hombre quien asume en su devenir interactivo una concepción del mundo.

\title{
2. LOS PRIMEROS POSITIVISMOS EN LA ANTROPOLOGÍA DE LA EDUCACIÓN
}

El concepto de «antropología», acaso debido a su amplitud, y en consecuencia a su indefinición, o en todo caso, a las múltiples posibilidades de desarrollo que encierra, ha sido entendido de muy diversa manera a lo largo de la historia, lo que ha dado lugar no sólo a diversas escuelas antropológicas y en su caso antropológico-educativas, sino a confusiones y posicionamientos radicales que de todas formas no han ayudado a la comprensión de lo antropológico-educativo y ni tan siquiera han servido para evolucionar de forma clara y segura dichos estudios.

En un principio y tal como su etimología da a entender, Antropología, era el estudio del hombre por lo que tales estudios se realizaron, básicamente desde dos posturas en verdad muy diversas, pero que obedecían a un mismo juego de intereses: el conocimiento positivo, certero del hombre; y a ello se aunaron tanto la ciencia (la biología, fundamentalmente) como la filosofía.

La perspectiva filosófica, trataba de profundizar en la esencia del ser humano -en lo que era verdaderamente el hombre- siguiendo para ello las tradiciones bien ontológicas o metafísicas propias de la Filosofía. Así, desde esta perspectiva, la antropología no tenía independencia epistemológica ya que se trataba de una síntesis de los discursos que sobre el hombre habían realizado las diversas escuelas o autores más relevantes en el mundo de la filosofía. De todas maneras, era más un problema de formas que de fondo ya que la «reacción antropológica» de manos de las filosofías vitalistas o positivistas, no eran sino una contestación metodológica al positivismo científico más que a su identidad.

Esta corriente influyó sobremanera en los estudios pedagógicos casi de forma mimética. Desde el posicionamiento filosófico se hablaba de Antropología Pedagógica (lo pedagógico como conocimiento alcanzado por vía de la racionalidad o del pensamiento especulativo) que se convertía en el estudio de los paradigmas humanos considerados valiosos y por tanto como objetivos alcanzables a través de la actividad educativa; evidentemente, estos paradigmas se trasvasaban directamente desde la filosofía, fundamen- 
talmente de manos del vitalismo historicista profesado por Dilthey (1965); a partir de él, Spranger (1948), Nohl (1974 y 1975), juntamente con Flitner (1972), que decantaron sus posiciones vitalistas hacia uno de los efectos de la historia -la cultura- (vitalismo culturalista), lograrán mantener tal tradición entre nosotros hasta más allá de los años cincuenta. Asimismo, esta línea filosófica se vio también refrendada, recibiendo un extraordinario impulso, a partir de la obra de Husserl y de la fenomenología en general, que luego, a través de Cassirer $(1979,1987,1991)$ y Brambled (1971) fundamentalmente, lograría aportar otro enfoque filosófico de la cultura (ya plenamente independizado de los neokantianos de Marburgo $)^{9}$ y de las formas simbólicas, que indudablemente refrendaban la posición ya anunciada en estas páginas y en su primer apartado, a propósito del interaccionismo simbólico-constructivista.

Tal como decíamos, la segunda opción a la hora de estudiar el hombre vino desde la Biología, o sea, desde posturas cientificistas y experimentales. No hay duda que la Biología en tanto ciencia de la vida tenía derecho a requerir para sí el estudio del hombre en su calidad de ser vivo. De ahí entonces que a la cuestión antropológica más paradigmática -qué es el hombre- la Biología constestase con sus armas, o sea con estudios antropométricos, que poco a poco se fueron desarrollando próximos a la bioquímica y a la genética. No hay duda, que del estudio de las características estructurales de las diversas razas, a las cuestiones que pretende desentrañar la biosociología o la genética, hay un trecho gigantesco, que sin embargo, ha sido salvado por la investigación científica.

Aunque parezca mentira, la Antropología Pedagógica de la época, estuvo también fuertemente mediatizada por el enfoque biológico; piénsese que si la educación pretendía formar al hombre y el hombre era a su vez considerado fundamentalmente como ser biológico, la pedagogía se convertía en auxiliar de la Biología cuando no en un subproducto o apéndice de la misma, tal como llegase a afirmar H. Spencer. Sólo así se entiende el sentido por el cual se propiciaron las colonias escolares en pleno siglo XIX, pues obedecían a la necesaria síntesis que debía darse entre pedagogía y biología. Sólo era factible educar si el niño estaba biológicamente bien desarrollado (como vemos la educación subsidiaria del estado biológico del niño) y en este sentido, las colonias ayudaban a esto, a educar de acuerdo a las características biológicas de la infancia, iniciándose así la corriente del activismo escolar, fundamentalmente, a partir de Dewey. No debe entonces sorprendernos que autores de tanta transcendencia pedagógica como María Montessoria publicase una Antropología pedagógica de base radicalmente biologicista.

9. A pesar de que el vitalismo en un principio pueda considerarse como una manifestación de las filosofías positivas, y por ello mismo denominadas también naturalistas, cabe tener en cuenta que por mor de la cuestión metodológica se alejan de la que podríamos denominar «razón material», que ahora estaría protagonizada por el método científico, para ir encontrando su posicionamiento «natural» en, o muy cerca de la «razón idealista», por lo que a fines del XIX y principios del XX aparece todo un movimiento de fervor neokantiano que tendrá su eje en Marburgo. Ello nos da pie para orientar una nueva perspectiva de estudio que se centraría en el análisis de nuestras preocupaciones que son objeto de este trabajo, en el ámbito hispano. Decimos esto porque no debe olvidarse que Ortega y Gasset estudió en Marburgo (cursos 1906 y 1907) siendo alumno de dos neokantianos muy interesados por la Pedagogía y con obra fundamental en este campo, tales como H. Cohen y P. Natorp, que dedicaron además esfuerzos en pro de la antropología pedagógica de corte vitalista-culturalista el primero, y de la pedagogía social el segundo. 
En países como el nuestro, de arraigado espíritu católico, estos enfoques materialistas no tuvieron apenas implantación, desarrollándose en todo caso los estudios antropológico-educativos bajo los planteamientos filosóficos ya analizados. No obstante, en las últimas décadas, enfoques tales como «fundamentos biológicos de la educación o de la personalidad» han pretendido con mayor o menor fortuna retomar y actualizar la cuestión biológico-educativa entre nosotros.

De todas formas, con la antropología de corte biologicista concurría la misma falta de independencia epistemológica que también acusaba la antropología filosófica. En ambos casos, como es fácil comprender, lo adjetivo, o sea, lo biológico y lo filosófico se manifestaba como las estructuras dominantes de tales saberes. Estudiar al hombre solamente desde la filosofía no era sino resucitar analíticamente una cuestión inverterada de la tradición filosófica más remota; por su parte, hacer lo mismo desde la biología no era más que refrendar el objetivo único de la biología humana.

Sólo será a través de un tercer enfoque cuando la Antropología irá encontrando su lugar epistemológico, o al menos con una parcela de la realidad de la que hará su objeto de estudio. Nos referimos claro está a la cultura, al fenómeno cultural en su sentido más amplio. Téngase en cuenta que lo cultural no era analizado ni estudiado por ninguna materia, independientemente de los posicionamientos abarcadores de la filosofía, de tal manera que, en el devenir del siglo XX, hablar de Antropología, ha significado de cada vez más referirse a la Antropología «Cultural».

No obstante el enfoque cultural de la antropología no es más moderno que los dos anteriores, ya que también tiene sus orígenes en el siglo XIX. De hecho, el enfoque cultural del estudio del hombre tiene su génesis en el movimiento cultural conocido como romanticismo; este redescubrir la naturaleza que fue el sueño del primer espíritu burgués, incluso en el terreno educativo -Rousseau, Pestalozzi, la propia ILE en Españafue quien a su vez se interesó por la naturaleza del hombre y por el hombre en relación a su medio natural (de ahí la «moda» romántica de los grandes viajeros en el XIX, siendo por cierto España uno de sus objetivos preferidos: Blanco White, Archiduque Salvador de Austria..., etc., que quiérase o no, aportaron los primeros documentos antropológicoculturales referidos a nuestro país). Si a ello añadimos la fuerte dosis historicista del momento, evidente en todos los ramos del conocimiento humano desde la literatura -bastaría recordar ahora «El señor de Membrive» hasta la arquitectura (revival del románico o del gótico, fundamentalmente), así como el descubrimiento de lo «popular», tendremos algunos de los vectores que conformarán el origen de la Antropología Cultural. Y como síntesis de todo ello, al menos en España, la Institución Libre de Enseñanza, y sus aportaciones a la recuperación y estudio de costumbres y tradiciones populares -el folklore- y su implantación pedagógica en la Escuela, tal como se evidencia a través del Boletín que publicaba la propia Institución.

Coligado a estos factores intervinientes en sus orígenes cabe citar también otro relacionado estrechamente con la política colonial de la propia burguesía. Nos referimos al pragmatismo anglosajón aplicado al gobierno de sus colonias llevada a cabo por el Reino Unido en el siglo XIX. Fueron los gobernantes de las diversas colonias británicas que en aras de la efectividad política y económica, intentaron conocer las costumbres y formas de vida de los pueblos dominados para así mantener unas cotas de respecto con sus tradiciones que permitiesen superar los posibles enfrentamientos. Para ello se rodearon de colaboradores cuya labor se centraba en el estudio de las formas de vida, valores, 
tradiciones, folklore en general y estructuras organizativas de los pueblos sometidos, considerándose tales documentos como las primigenias formas que alumbran lo que luego se denominaría Antropología Cultural.

Sin embargo, este nuevo enfoque, más o menos paralelo en el tiempo a los anteriores, tampoco ha podido solucionar el problema epistemológico de la Antropología, que sigue refiriéndose a su objeto de estudio -el hombre- a través de sus manifestaciones, o sea, indirectamente, mediatizando su función a través de otros desarrollos (sin estudiarlo nunca directamente) tal como sucede con la filosofía, la biología o ahora, la cultura. Asimismo, y en los últimos años, ha sido también notoria la incidencia de la psicología (Linton, Mead...) ya que al enfrentarse el antropólogo al tema de la conformación cultural de los pueblos se ha interesado en comprobar cómo los procesos de endoculturización influyen en la personalidad humana, en sus pautas sexuales, o incluso, en sus formas de pensar (antropología cognitiva, de reciente configuración).

Así pues, consideramos hoy a la Antropología como un sistema científico abarcador de las múltiples aportaciones de las ciencias humanas (y físicas), estructuradas alrededor del concepto y del fenómeno cultural; tiene pues una visión globalizadora e integradora, más que de delineamiento original de su campo de estudio. Tanto es así, que cara al futuro y vista la tendencia a la uniformización cultural de la humanidad, vemos a la antropología más centrada en posibilitar una visión sintética y de conjunto, de las aportaciones de las diversas ciencias humanas. Una visión antropológica de un fenómeno humano sería entonces desarrollar una síntesis de sus especificidades económicas, sociológicas, psíquicas, educativas... etc., para al fin hipotetizar el modelo cultural conformado, y ver luego cómo esta aporte cultural refuerza, modifica sus pautas de comportamiento social, económico, psíquico, educativo, etc. Lo cultural pues como referente activo y pasivo de conformación de una comunidad o sociedad humana, y la antropología como la estructura conceptual que mediatizada por las restantes ciencias humanas logra conformar un concepto específico de cultura, cuyo funcionamiento y dinámica es a su vez estudiado en aquella misma sociedad. O si se quiere, la antropología como ciencia de ida y vuelta basculando sobre el significado de lo cultural, y lo cultural como síntesis de todas las manifestaciones comunitarias y a la vez como motor modificador o refrendador de las mismas.

Por lo que afecta a la «antropología pedagógica», y coligado a lo visto hasta ahora no hay duda de que podemos hablar de tres modelos o enfoques, a saber: desarrollar una antropología pedagógica de base biologicista, o bien contextualizada en el discurso filosófico, o en último caso, considerando a la educación como un elemento conformador de lo cultural y con posibilidad de ser a su vez modificado por la propia cultura.

\section{EL OBJETO DE LA ANTROPOLOGÍA DE LA EDUCACIÓN}

En educación tenemos pues tres modelos antropológicos en que basarnos, y la elección sólo debe realizarse de acuerdo con el objetivo último que buscamos a la hora de investigar o estudiar antropología de la educación. Indudablemente este análisis de objetivos adquiere mayor importancia cuando se trata de una labor curricular, tal como los nuevos planes de estudio de la licenciatura de Pedagogía suponen, al incluir la Antropología de la educación como material troncal en el primer o segundo curso. 
Si se considera que la antropología de la educación debe servir para iniciar al estudiante en las cuestiones filosóficas de la educación, es evidente que no tendremos problema alguno en seleccionar como modelo orientador a la antropología filosófica; se tratará en definitiva de estudiar las opciones humanísticas filosóficas que puedan constituir modelos valiosos, en el plano moral y axiológico, de educación.

Si lo que se quiere es materializar una introducción pedagógica orientada exclusivamente a las cuestiones patológicas (tanto psíquicas como biológico-somáticas) que puedan tener interés para posteriores estudios propios de la educación especial, parecerá más aconsejable introducir la concepción biológica como orientadora de la antropología de la educación. Ahora bien, si se pretende, que parece ser ha sido la voluntad del legislador, iniciar los estudios pedagógicos a través de la antropología de la educación, y que en consecuencia, tal materia sirva de primer contacto con la realidad pedagógica, parece ser consecuente que, por sus características intrínsecas, tengamos que abonarnos al modelo culturalista (independientemente claro está de las concepciones eclécticas o de síntesis). El modelo cultural plantea una visión muy amplia y global, que además tiende a descubrir los mecanismos culturales en relación con toda la fenomenología humano-social de que es capaz el hombre; de esta forma analizará lo cultural en la sociedad, en la política, en las instituciones (familia...), etc. y por extensión, cualquier producción efectuada en estos contextos por el propio hombre. Asimismo, siempre que la sexualidad, la personalidad, las formas de aprendizaje, la visión del mundo que se posea, el pensamiento, etc., se vea mediatizado por lo cultural también será objeto de estudio de la Antropología. En este sentido quizá sea importante recordar la definición clásica de Tylor ${ }^{10}$.

«La cultura o civilización, en sentido etnográfico amplio, es aquel todo complejo que incluye el conocimiento, las creencias, el arte, la moral, el derecho, las costumbres y cualesquiera otros hábitos y capacidades adquiridos por el hombre en cuanto miembro de la sociedad» (Tylor, 1975, p. 29).

Hoy en día y teniendo en cuenta la evolución de la propia Antropología Cultural y de las sociedades actuales creemos que el estudio de la Antropología tendría que contemplar:

1. Comprensión de la cultura en tanto totalidad de las manifestaciones humanas.

2. Convergencia obligada entonces con las demás ciencias humano-sociales.

3. Debe contemplar no sólo los resortes comprensivos de unas sociedades determinadas sino fundamentalmente debe tender a la comprensión y solución de los problemas actuales de la humanidad, por lo que debe

- promover el entendimiento entre las culturas

- orientar los cambios socioculturales

- mejorar la unidad y el progreso de la humanidad

- aportar claves de comprensión intercultural

- favorecer la igualdad, justicia y libertad de los pueblos

4. Para asumir tales logros debe ser consciente del tipo de sociedad en la que nos encontramos y favorecer su desarrollo justo y armónico. Ello supone la comprensión de lo urbano y tecnológico para así promover:

10. Sobre el concepto de cultura y su relación con el de civilización, véase Kahn, J. S. (1975), El concepto de cultura: textos fundamentales, Anagrama, Barcelona. 
- la crítica social

- la ingeniería social

- los programas de cambio social

- la participación ciudadana

- la toma de conciencia hacia el cambio

5. En consecuencia, la antropología debe trabajar más hacia lo que debe ser la sociedad y el hombre, en vez de estudiar lo que es.

Ante este diseño efectuado no cabe duda que la educación no es ajena al mismo ya que:

1. La educación se integra en el mundo cultural como generadora de cultura y como fenómeno influido por la propia cultura. Asimismo, la Pedagogía tiene una vocación totalizante ya que pretende estudiar cualquier fenómeno educativo (formal, no formal e informal).

2. La educación se integra dentro de objeto de conocimiento de las ciencias humanas y sociales coordinándose con todas ellas (enfoque de las ciencias de la educación).

3. La educación dentro de sus coordenadas pretende también resolver los problemas de la humanidad y del individuo, orientándose hacia valores de comprensión, pacifismo y relación entre las gentes y los pueblos. Es por otra parte transmisores de valores.

4. La educación conjuga un papel activo en los programas de cambio social, estando atenta a las nuevas problemáticas que van surgiendo, a fin de aportar soluciones desde su campo de acción (educación ambiental, educación para la paz, educación intercultural, integración de la tecnología, programas de formación en las ciudades, etc.).

5. La educación también se preocupa por el deber ser, más que por lo que es.

Desde esta perspectiva, no hay duda, que la educación puede integrarse en el contexto de lo antropológico con las mismas orientaciones que la más actual Antropología, por lo que no debe extrañarnos de que haya sido considerada como objeto de su estudio (Spindler, 1963 y 1965; Nicholson, 1969; Kneller, 1974).

Así pues y bajo el paradigma cultural, la Antropología de la Educación se abre a un espacio amplio en donde la cuestión humana, la productividad cultural y la acción educativa se enlazan, se entremezclan, se condicionan y se re-crean constantemente, por lo que se reconvierte en el estudio de las incidencias culturales sobre la educación del hombre, al mismo tiempo que contempla también como la educación presupone un objetivo cultural al adecuarse a paradigmas culturales determinados, siendo a su vez productorareproductora de cultura. Ello hace que el estudio de la educación, integrado en este amplio contexto, se vea siempre en relación con todos los fenómenos humanos y sociales, por lo que aporta una visión sistémica, global, realista y articulada del fenómeno educativo.

Para nosotros, pues, la Antropología de la Educación, visto el amplio campo de intereses, que abarca, se convierte en una perspectiva o un enfoque comprensivo de la educación en relación fundamental con el mundo cultural o sea, contemplando aspectos tales como la política, la sociedad, las instituciones... etc., teniendo en cuenta que todo ello afecta al hombre ya que son elementos que inciden en su constructividad. De una forma más esquemática podríamos hablar de tres grandes esferas de la Antropología de la Educación, que sin ánimo de exhaustividad, al menos daría lugar a las siguientes áreas y subámbitos de reflexión y aplicación: 
1. La educación como fenómeno cultural:

- el enfoque educativo en los distintos pueblos y culturas, así como en épocas anteriores (la «educación de los pueblos» de la que hablaría Schneider). Hoy toma gran importancia visto el proyecto de la Unión Europea.

- incidencia de lo cultural en el diseño curricular, en los procesos de aprendizaje y en general en el aula (Etnografía, currículum oculto, pensamiento del profesor, como temas más novedosos)

- incidencia de lo cultural en los comportamientos, en las costumbres, en los juegos, y por tanto en la socialización de niños, jóvenes y adultos.

Temas tales como ocio, tiempo libre, mass media, comics, tribus juveniles, serían algunas de sus últimas manifestaciones.

- incidencia de lo cultural en la conformación de la personalidad

- incidencia de lo cultural en las instituciones educativas así como en cualquier elemento pedagógico, incluida la tradición pedagógica.

2. La cultura como elemento educativo

- los estudios críticos sobre los núcleos curriculares

- los aportes metodológicos (experimentalismo, cualitativismo..., etc., que no dejan de ser consecuencias culturales con incidencia en la construcción pedagógica y en la comprensión de la educación)

- las culturas específicas de gran incidencia formativa: familiar, grupo de pares, la ciudad, los contenidos de los mass media...

- la cultura popular y su integración en los curriculums y en general en las actividades escolares

- la literatura infantil, y otros aportes culturales con propiedad para ser integrados en programas educativos

- los ambientes culturales determinantes de tantas características infantiles (comunidad, barrio, cultura de los grupos de origen)

3. La aplicación educativa y/o la práctica escolar

- programas de europeísmo

- programas multiculturales o interculturales

- los estudios etnográficos

- programas de educación no formal, y de educación diferenciada (para grupos de edad, o grupos sexuales..., etc.)

- la gestión cultural y las políticas culturales (que poseen sistemas pedagógicos para su implantación y desarrollo)

- la profesionalización pedagógica para estas nuevas prácticas educativo-culturales: educadores de calle, monitores..., etc.

La Antropología de la Educación nos plantea cómo el hombre llega a ser (educado) en función de las variables culturales intervinientes. Desde esta perspectiva, el constructivismo sería el paradigma que pretende desentrañar la Antropología de la Educación a base de explicitar la fenomenología posibilista de tal constructividad. Así pues, y en este sentido amplio con que dotamos a la Antropología de la Educación, ésta se nos presenta como el estudio de las variables biológicas, psíquicas, sociales, políticas, culturales, religiosas, etc., que mediante la educación conducen al constructivismo unitario de la persona.

En definitiva y con tal planteamiento, nuestra Antropología de la Educación supera ampliamente los límites de una materia o disciplina para, tal como decíamos, convertirse en un enfoque comprensivo de lo educativo y de la constructividad humana mediante la 
educación. La Antropología de la Educación es pues una forma actual, abierta hacia el futuro, de entender la Pedagogía y de integrar, bajo un lenguaje más novedoso y adaptado a nuestro tiempo y circunstancia, el discurso pedagógico.

\section{BIBLIOGRAFÍA}

BECK, U. (1986). Risikogesellschaft, Suhrkamp, Frankfurt.

BECK, U. (1993). «De la sociedad industrial a la sociedad del riesgo. Cuestiones de supervivencia, estructura social e ilustración ecológica», en Revista de Occidente, Noviembre de 1993, núm. 150

Berger, P./Luckmann, Th. (1991). The Social Construction of Reality, Penguin, Londres.

BRAMELD, Th. (1971). Bases culturales de la educación, EUDEBA, Buenos Aires.

CASSIRER, E. (1979). Filosofía de las formas simbólicas, F.C.E. México.

CASSIRER, E. (1987). Antropología Filosófica, F.C.E. México.

CASSIRER, E. (1991). Esencia y efecto del concepto de símbolo, F.C.E. México.

Dilthey, W. (1965). Fundamentos de un sistema de pedagogía, Losada, Buenos Aires.

FLITNER, W. (1972). Manual de pedagogía general, Herder, Barcelona.

GEERTZ, C. (1991). La interpretación de las culturas, Gedisa, Barcelona.

GeHLEn, A. (1993). Antropología filosófica, Paidós, Barcelona.

Hegel, G. W. F. (1981). Fenomenología del espíritu, F.C.E. México.

HeIDEgGer, M. (1979). Sein und Zeit, Niemeyer, Tubinga (Trad. cast. en F.C.E. México).

JASPERS, K. (1983). Einführung in die Philosophie, Piper, Munich (Trad. cast. en F.C.E México).

KNELleR, G. F. (1974). Introducción a la antropología educacional, Paidós, Buenos Aires.

MEAD, G. H. (1982). Espíritu, persona y sociedad, Paidós, Barcelona.

Nicholson, C. (1969). Antropología y educación, Paidós, Buenos Aires.

NoHL, H. (1968). Teoría de la educación, Losada, Buenos Aires.

NoHL, H. (1974). Antropología Pedagógica, F.C.E. México.

PLESSNER, H. (1975). Die Stufen des Organischen und der Mensch, Gruyter, Berlín.

SARTRE, J. P. (1961). El ser y la nada, Ibero-americana, Buenos Aires.

SPINDLER, G. D. (1963). Education and culture, Holt, Richard \& Winston, New York.

SPINDLER, G. D. (1965). Education and anthropology, Stanford University Press, Stanford, Ca.

SPRANGER, E. (1949). Cultura y Educación (2 volms), Espasa-Calpe, Buenos Aires.

STEINER, G. (1991). En el castilo de Barba Azul, Edit. Gedisa, Barcelona.

TYLOR, E. B. (1975). «La ciencia de la cultura», en KAHN, J. S., El concepto de cultura: textos fundamentales, Anagrama, Barcelona.

WeBER, M. (1987). Economía y sociedad. Esbozo de sociología comprensiva, F.C.E., México. 